\title{
LAS TRES CORRIENTES DE PENSAMIENTO Y ACCIÓN DENTRO DEL CAMPO DE LA ECONOMÍA SOCIAL Y SOLIDARIA
}

\author{
José Luis Coraggio
}

\begin{abstract}
R E S U M E N El artículo se propone distinguiry revistar la existencia de distintas corrientes actualmente vigentes en el campo de prácticas de la economía social y solidaria (ESS), tanto a nivel del pensamiento como de la acción. Se presentan tres "corrientes" denominadas como tales en tanto entre los actores, fundamentalmente promotores, predomina una u otra práctica y visión sobre el alcance de la ESS.

La primera corriente procura la (re)inserción a través del trabajo actuando a nivel microeconómico y focalizando en el alivio de la pobreza. La segunda, promueve la creación de un sector orgánico (subsistema) de ESS y problematizan la sostenibilidad y eficiencia de los emprendimientos promovidos. Por su parte, la tercera corriente piensa y actúa también a nivel sistémico, proponiendo la construcción de Otra Economía. Desde esta última, no se trata de corrientes sino de tres niveles de intervención que se necesitan mutuamente para poder concretarse.
\end{abstract}

P A L A B R A S - C L A V E economía socialy solidaria (ESS); economía mixta; economía plural; luta contrahegemónica; Otra Economía.

\section{INTRODUCCIÓN}

En las dos últimas décadas, junto con los procesos de empobrecimiento y exclusión de masas de la población emergieron una diversidad de prácticas y formas económicas, en buena medida ya institucionalizadas, que se ubican bajo el paraguas de la ESS o de la Economía Solidaria (por propia auto-denominación o por quienes las caracterizan así desde afuera). Micro-emprendimientos asociativos, trabajadores o usuarios auto-gestionados, empresas recuperadas, comercio justo, microcrédito, redes de abastecimiento o comercialización, etc.

En lo inmediato, todas se dirigen con prioridad al segmento de los pobres o excluidos, y marcan su intención de diferenciarse de las prácticas asistencialistas (que no es lo mismo que asistenciales, pues siempre es necesaria una dosis de asistencia), atacando la cuestión social desde la (re) inserción en la economía que operó los efectos excluyentes.

Hay otras prácticas cuya legitimidad como parte de la ESS es puesta en duda por algunas nuevas corrientes y que reclaman para sí el adjetivo de "economía social", "solidaria" o de "ESS". Por ejemplo: las cooperativas tradicionales, las asociaciones (generalmente sin objetivos pecuniarios) y las mutuales de diverso tipo, todas ellas 
1 Ver: <http://www.ciriec ula.ve/callforpapersSEspanishformat.pdf>.
2 Ver: Jean-Louis Laville (Comp.), Economía social y solidaria. Uma visión europea, UNGS/ALTAMIRA, Buenos Aires, 2004. formalizadas, incluso siguiendo estatutos legales que han sido uniformados a través de los continentes. Hay también prácticas que nadie pensó en incorporar, como las de los sindicatos o la del presupuesto participativo y, desde otro lado, las comunidades indígenas. Finalmente otras que - sobre todo en Europa - son cuestionadas por su sesgo empresarial, como las empresas sociales, organizadas como empresas de capital pero con objetivos sociales. Otro ejemplo es el la llamada "responsabilidad social de las empresas". ¿Tiene algo que ver con la ESS? En todo caso, se hace evidente que el recurso usual de definir una categoría por enumeración de casos no es fácil de aplicar.

Tomemos un punto de partida autorizado. Para el Centro Canadiense de la Economía Social, ésta es definida así:

La Economía Social se distingue del sector privado y del sector público e incluye las cooperativas, las fundaciones, las cooperativas de ahorro y crédito, mutualidades, organizaciones no gubernamentales, el sector voluntario, las organizaciones benéficas y las empresas sociales. ${ }^{1}$

Así, incluyen las ONGs y las fundaciones, que pueden estar financiadas por grandes empresas privadas, y a la vez excluyen al "sector privado". Por sector privado se refieren a las empresas con fines de lucro, pero incluyen las empresas sociales y excluyen a las empresas públicas. Excluyen al sector público y, por tanto, sus empresas públicas, sus programas de asistencia social, algo en que prácticamente todos van a coincidir, pero incluyen a las empresas que tienen fines "sociales" y las organizaciones benéficas. Cabe hacer la pregunta: ¿qué tienen en común las formas que entran en esta enumeración y qué las diferencia de las que no incluyen?

Si se adopta esta clasificación, habrá un debate sobre qué relación (externa) hay que tener con el estado dejado fuera de la ESS. Al presentar la economía mixta, hemos propuesto una definición de economía solidaria que incluye una parte del sector público, por ejemplo el presupuesto participativo o los servicios públicos, y que reconoce que las ONGs y fundaciones pero también las empresas con cogestión obrera pueden ser formas con elementos de solidaridad a considerar. Ni ellos ni nadie incluye a los sindicatos, nosotros proponemos que sus luchas y acciones colectivas sí son (o pueden ser) parte de la ESS... Y las comunidades étnicas, de ser reconocidas, suelen ser vistas como "otra cosa", lo que implica ajustar el concepto de racionalidad económica a la lógica instrumental de la acumulación y no de la racionalidad reproductiva, propia de la ESS que propugnamos.

Por otro lado, tenemos la propuesta llamada del Tercer Sector, definido por la negativa: está integrado por "organizaciones $\underline{\sin }$ fines de lucro". Prácticamente queda sólo un conjunto de ONGs y Fundaciones.

Llama la tención que incluyen a este sector, una parte importante del cual está financiado por fundaciones empresarias privadas, pero excluyen al estado que también es sin fines de lucro. Excluyen también a las cooperativas que no son empresas de capital que buscan lucrar sin límite sino que, hasta por estatuto, tienen que cumplir funciones sociales. Respecto a esta corriente, que predomina en el mundo anglófono, Jean-Louis Laville, un exponente de la ESS en Europa, particularmente en el mundo francófono, pero no solamente, pugna por diferenciarlas de la ESS. ${ }^{2}$

El espacio de acción de las prácticas que ejemplificarían la ESS es, entonces, muy heterogéneo y con bordes poco claros o, al menos, no consensuados. Anticipamos que 
las propuestas más complejas (y políticas), como es usual, abren lugar a diferencias ideológicas a veces muy marcadas. A nuestro juicio y el de Laville, la ESS es un sub-campo del campo de prácticas económicas que está cruzado con el campo de la política. Mientras para autores como Alain Caillé la política es una esfera diferenciada de la economía, para nosotros está ya en el interior mismo de la definición sustantiva de economía. ${ }^{3}$

Si los sistemas económicos son construcciones socio-políticas y no resultado de evoluciones naturales y necesarias, como propugnaría la visión de una secuencia de modos de producción de marxismo vulgar, o la de la evolución necesaria hacia una sociedad de mercado (el "fin de la historia" de Fukuyama), es preciso pensar la posibilidad de otra economía desde la lucha política contra-hegemónica, tratando de desestructurar la cultura económica capitalista, sumando a esto lo que consideramos ineludible: criticar su modo de definir y ejercer la autoridad social. Esto es así, tanto si se ejerce como poder de dominación vertical, donde los subordinados tienen que obedecer, como si, en el mejor de los casos, se ejerce como hegemonía, que se basa en convencer a los subordinados, que incluso pueden aportar voluntariamente para hacer más férrea la asimetría entre el arriba y el abajo. Ninguno es realmente democrático (donde el pueblo es el soberano).

En este marco de inevitable problematización sobre qué es y que abarca la ESS, y partiendo de las prácticas mismas, proponemos que pueden delinearse tres corrientes de pensamiento y acción, más o menos virtuales, más o menos reales, que el sentido común de los mismos activistas latinoamericanos tiende a reducir, como veremos, a la primera o, eventualmente, la extiende a la segunda. ${ }^{4}$

\section{La primera corriente, que procura la (re) inserción por el trabajo actuando} a nivel microeconómico, se caracteriza por un conjunto de prácticas que se focalizan en lograr la integración social, y en el alivio de la pobreza vía re-inserción (o la primera inserción) de grupos de personas excluidas del mercado de trabajo. Así, promover y apoyar el surgimiento de emprendimientos asociativos locales, gestionados por sus trabajadores-propietarios va en la dirección del autoempleo. Para las estadísticas dejarán de aparecer como desocupados, aunque puedan ser sub-ocupados o "improductivos" según las categorías neoclásicas del análisis de este cuasi-mercado. Eso va acompañado de una serie de prácticas más específicas, en buena medida ya institucionalizadas (véanse las cartillas que enseñan cómo promover o cómo organizar micro-emprendimientos), que intentan crear las condiciones que requieren esos emprendimientos para prosperar:

(a) formación: inyección de espíritu de empresa, contabilidad, conocimientos sobre los trámites u otras relaciones con el estado, identificación de mercados potenciales, métodos de propaganda y comercialización, selección de técnicas de producción, gestión elemental del negocio y, muy importante para muchos promotores, una nueva cultura de separación del emprendimiento y la familia...

(b) donación de una dotación de medios de producción iniciales o un crédito inicial para adquirirlos ("igualdad de oportunidades"),

(c) dar acceso recurrente a crédito para acompañar el proceso de consolidación o para atender necesidades de consumo de los emprendedores.
3 Ver: Alain Caillé, Jean-Louis Laville, Cyrille Ferraton y José L. Coraggio (Org.), ¿Qué es lo económico? Materiales para um debate necessário contra el fatalismo, ICCUS, Buenos Aires, 2009.

4 En lo que sigue implícitamente suponemos que las corrientes son encarnadas en los promotores, pero obviamente pueden estarlo en los actores mismos de la ESS. 
5 Ver: José L. Coraggio, Economía y política. Sobre la sostenibilidad de los emprendimientos mercantiles de la economia social, em J. L. Coraggio, Economía Social, acción pública y política, CICCUS, Buenos Aires, 2007.

6 Organismos como el Banco Mundial han mostrado uma gran capacidade para tomar y resignificar los términos que va proponiendo la ESS: microcrédito, participación, etc.
En general, esta corriente, preocupada por lograr la sustentabilidad de los emprendimientos mercantiles, tiene como paradigma la empresa de capital (explícita o implícitamente): su modo de cálculo de los costos y resultados, el concepto de "ganancia" y de "capital", pero sobre todo su concepto de eficiencia y por tanto de racionalidad. ${ }^{5}$

Esto da lugar a prácticas que ya están claramente institucionalizadas: el microcrédito, las incubadoras de emprendimientos mercantiles, las mismas cartillas de formación, etc. y a la búsqueda de regulaciones que reconozcan a estas formas en su especificidad y faciliten su funcionamiento: que puedan facturar sus compras y ventas, pagar o ser exentos de impuestos, recibir apoyos del estado, tener acceso a crédito, etc.

Otra característica es la separación propugnada entre el micro-emprendimiento (visto como semilla de una microempresa) y la economía doméstica/familiar o comunitaria (que no pertenece al ámbito del mercado). Asimismo se busca evitar la proliferación de emprendimientos unipersonales por cuenta propia, afirmando la necesidad de alcanzar escalas mínimas requeridas para alcanzar la eficiencia, es decir, la competitividad. Esto último, para formas de producción intensivas en fuerza de trabajo, implica que los emprendimientos deben estar formados por un grupo de trabajadores asociados que cooperan, creando así una capacidad mayor que la suma de las individuales, que procuran asumir el productivismo por trabajador como criterio de organización interno. El asociacionismo "utilitario", la absolutización del interés material de los trabajadores, es característico de esta corriente.

Estas prácticas de promoción son de nivel microeconómico en el sentido crematístico, y no dejan de serlo porque piensen en cadenas de valor, mecanismos de abastecimiento o comercialización conjunta, etc. pues las relaciones así consideradas son exclusivamente de intercambio en base a contratos según las leyes del mercado o sus variaciones (acuerdos de conveniencia que se rompen cuando el cálculo indica que hay opciones mejores). Los promotores pueden ser ONGs pero también programas de gobierno financiados e impulsados desde organismos internacionales. ${ }^{6}$ Aunque no son empresas se adscriben a la racionalidad instrumental, no plantean una crítica al mercado como institución y se concentran en lograr una producción y circulación de mercancías competitiva y procurando el mayor valor neto posible para esos trabajadores/propietarios.

Dándole otro énfasis a la caracterización, cuando es reduccionista, esta opción podría también denominarse "integracionista", pues afirma que el papel de las nuevas (o viejas, reactivadas o renovadas) formas económicas es llenar el vacío que deja el mercado capitalista global, y que deberían integrar a los trabajadores excedentes y sostenerse sobre la base de sus propios resultados produciendo eficientemente y compitiendo entre sí y con las empresas capitalistas en los mismos mercados.

Agreguemos a todo lo dicho que estas prácticas suelen estar dirigidas a los sectores más pobres, lo que establece un punto de partida que marca todo el proceso de promoción.

\section{Una segunda corriente, la que procura la creación de un sector orgánico}

(subsistema) de ESS, estaría conformada por las prácticas que, iniciadas como las anteriormente descriptas o saltando "etapas", van más allá, al advertir que la sostenibilidad de las formas económicas promovidas no se logra sólo con (i) la eventual articulación de los micro-emprendimientos asociativos a través de relaciones oportunistas de mercado, y (ii) una mayor eficiencia definida como la de las empresas (rentabilidad monetaria). Se advierte que hacen falta redes no meramente económicas, sino de reciprocidades, de solidaridades sociales y políticas. Esas solidaridades se espera 
que se concreten en la formación de sujetos colectivos, como asociaciones locales pro desarrollo local, o diversas sectoriales y transversales de trabajadores autogestionados.

En este caso, desde el comienzo de la intervención se trata de evitar la fragmentación de los emprendimientos y promover la conformación de un sector articulado orgánico. Por "orgánico" nos referimos a algo más que una sumatoria mecánica, como cuando se asocian productores para reclamar mejores precios. La palabra apela a la idea de un subsistema de partes que cumplen funciones en un todo interdependiente y que, en el caso de un organismo social, conlleva la emergencia de un sujeto colectivo con capacidad de responder al contexto, como subsistema.

Se trata también de incluir el proceso económico en su conjunto: producción, distribución, circulación y consumo, generando asociaciones de productores, de comerciantes, de financiadores, de consumidores, pero además articulaciones conscientes entre todos ellos como actores o sujetos. Se trata además de incluir las acciones para lograr mejores relaciones de reciprocidad y redistribución a través del estado: asignaciones monetarias, ingreso ciudadano, tasas de interés, tasa e impuestos, acceso a bienes públicos (salud, educación, servicios subsidiados como el de transporte, energía, agua, etc.). Pues sin ellas faltaría un piso básico que protege a los productores contra la alta vulnerabilidad de sus emprendimientos.

Implica partir de la economía popular y su cultura colonizada, subordinada e individualista, pero apoyándose en componentes solidarios sin los cuales no se lograría la sobrevivencia, incluyendo en los programas a: (i) trabajadores individuales procurando su asociación en algún nivel (artesanos que comercializan juntos, campesino que no quieren compartir la tierra pero sí un tractor o un crédito para canales de riego, etc.), (ii) emprendimientos familiares.

Se incluye y promueve como actividad económica del subsistema la producción para el autoconsumo familiar o comunitaria (huertos, infraestructuras, etc.). Se trata también de no ver a la escuela pública formal como contexto externo sino de integrar sus elementos (maestros, alumnos, currículo) como parte del sector. Otro tanto con los centros de salud...

Es evidente la diferencia en los enfoques conceptuales, pero lo principal es que hay claras consecuencias sobre las prácticas. Así, para la segunda corriente no se trata solamente de:

(a) partir de un grupo de individuos, ver qué pueden producir y cuáles son las condiciones para que se organicen para hacerlo y poder sostenerse a partir de los resultados de mercado, para luego,

(b) dados los problemas que se van dando de comercialización, de abastecimiento, o de pérdida del valor agregado a manos de los intermediarios, etc. pensar en armar "cadenas de valor" articulando emprendedores en distintos eslabones.

Lo anterior son relaciones de mercado que se dan al primer nivel, el microeconómico. Por lo demás, esas relaciones de mercado pueden estar centralizadas por empresas de capital, como pueden ser los supermercados como subcontratantes que dominan las cadenas de abastecimiento e imponen productos, tecnologías, costos. En cambio de trata de construir incluso lo microeconómico, comenzando por una anticipación de las cadenas posibles y desde allí lograr que actores o sujetos vayan generando más o menos paralelamente los emprendimientos que van a articularse 
(ejemplo: no comienzo con productores textiles a partir de materias primas compradas y con bocas de salida usuales, sino que ya se incluyen de entrada los participantes potenciales para cubrir cada eslabón de la cadena: productores de lana, transportistas, productores de hilo, de tejidos, confeccionadores, comercializadores, entidades o mecanismos de financiamiento, vinculación con agencias de asesoría tecnológica, etc. O por lo menos lo tenemos como horizonte antes de que el aislamiento sea un problema, mientras vamos avanzando con grupos de productores que se van organizando y compartiendo esa visión... No es entonces un resultado del mecanismo de mercado sino una construcción consciente que puede además tener otros objetivos (ejemplo: la seguridad alimentaria, aunque no sea "eficiente").

Para dar un ejemplo: en esta perspectiva no alcanza con el crédito personal y pequeño sino que se requiere un sistema de ahorro y crédito de otra escala, con fondos públicos de garantía que le permitan prestar para actividades productivas o con un período más largo de recuperación (como las inversiones en infraestructura) y con modalidades que admiten tomadores de crédito colectivos. Algo por construir que será parte de la ESS si se trata de un sistema de finanzas SOLIDARIAS, autogestionado democráticamente. Y su sostenibilidad no será solo financiera sino social, por la existencia de relaciones solidarias con la comunidad, entre los participantes.

\section{EL CONCEPTO DE ECONOMÍA MIXTA: ECONOMÍA EMPRESARIAL CAPITALISTA, ECONOMÍA PÚBLICA, ECONOMÍA POPULAR Y SU RELACIÓN CON EL SECTOR Y/O LOS PRINCIPIOS DE LA ESS. EL ALCANCE DE LA SEGUNDA CORRIENTE}

Toda economía puede ser analizada como compuesta por tres sectores o formas de organizar los procesos económicos: (a) el empresarial privado, (b) el del estado o público, (c) el de economía popular.

El de economía empresarial privada es un sector que se organiza como un subsistema más o menos articulado de empresas de capital. El sentido del sector, transmitido a la subjetividad de los empresarios, es acumular capital, ganar sin límite, y para ello competir y ganar y, para lograrlo, aplicar la racionalidad instrumental. Según la ideología económica hegemónica, para sobrevivir en el sistema de mercado, toda forma económica tiene que asumir esos criterios, sea el estado, una ONG, o un emprendimiento familiar (esto no garantiza que efectivamente sobrevivan, incluso las empresas de capital, que quiebran de a decenas de miles cada año). En una sociedad capitalista, el tipo ideal de empresa de capital, el que Weber planteó como la forma superior de la organización económica, se ha convertido además en el paradigma de la organización racional en general (teoría de la acción racional). Sus categorías fundamentales son: capital invertido, costos, ingresos, ganancias media por su masa o por su tasa respecto al capital, estructura del capital (fijo, circulante, etc.), crédito, riesgo,... Su articulación está dada por el mercado, pero en el mercado real se forman y actúan grupos económicos concentrados, sistemas de clusters y subcontratación, hay empresas formadoras de precios, etc. que operan lejos de la utopía del mercado competitivo de libre concurrencia. 
El sector de economía estatal o pública abarca las unidades administrativas de organización de los estados: instancias de gobierno central, presidencia, ministerios, provincias, municipios, empresas públicas, organizaciones que proveen servicios públicos (como la escuela o el hospital), y para funcionar requieren recursos económicos que provienen del sistema fiscal de redistribución, de lo que producen sus empresas o del crédito. Su sentido, no siempre es el mismo para cada partido de gobierno o para cada segmento del subsistema. En general pueden ser: incentivar y orientar la inversión y el proceso de crecimiento nacional, asegurar la gobernabilidad del sistema, acumular poder y, finalmente: lograr el bien común. Uno puede subordinar a los demás, o darse una combinación más pareja de todos ellos. Sus categorías centrales son: presupuesto, gasto, ingresos fiscales, deuda pública, déficit o superávit, tasas de interés ("riesgo país")... Su articulación está dada por la rígida estructura burocrática y verticalista que une sus elementos.

El sector de economía popular tiene como base de organización económica las unidades domésticas, básicamente los hogares, sus extensiones (organizaciones económicas de diverso tipo) y las comunidades. Este sector, lejos de estar articulado como tal, es magmático, fluye, cambia de formas. Puede pasar de un peso importante de la inserción en el mercado de trabajo en relación de dependencia a la multiplicación de emprendimientos, cooperativas, asociaciones, mutuales. Puede pasar de comunidades bien consolidadas a comunidades en proceso de desintegración por la migración, la dependencia del mercado, etc. Si acumula es a niveles elementales, como inversión inmediata para los emprendimientos, o en la vivienda y sus instalaciones (esta acumulación no es de capital, sino de formas de la riqueza para su uso). Su sentido es la reproducción biológica y social de la vida de sus miembros en las mejores condiciones posibles. Sus categorías principales son: ingresos, consumo, hibridación de recursos, oportunidades de trabajo, emprendimientos, programas asistenciales, ayuda mutua, condiciones y calidad de vida... Su articulación está dada por relaciones de mercado (generalmente altamente competitivas), así como por relaciones de redistribución y reciprocidad vinculadas a diversos tipos de afinidades.

A nivel agregado (macro) podemos graficar la economía mixta como sigue:

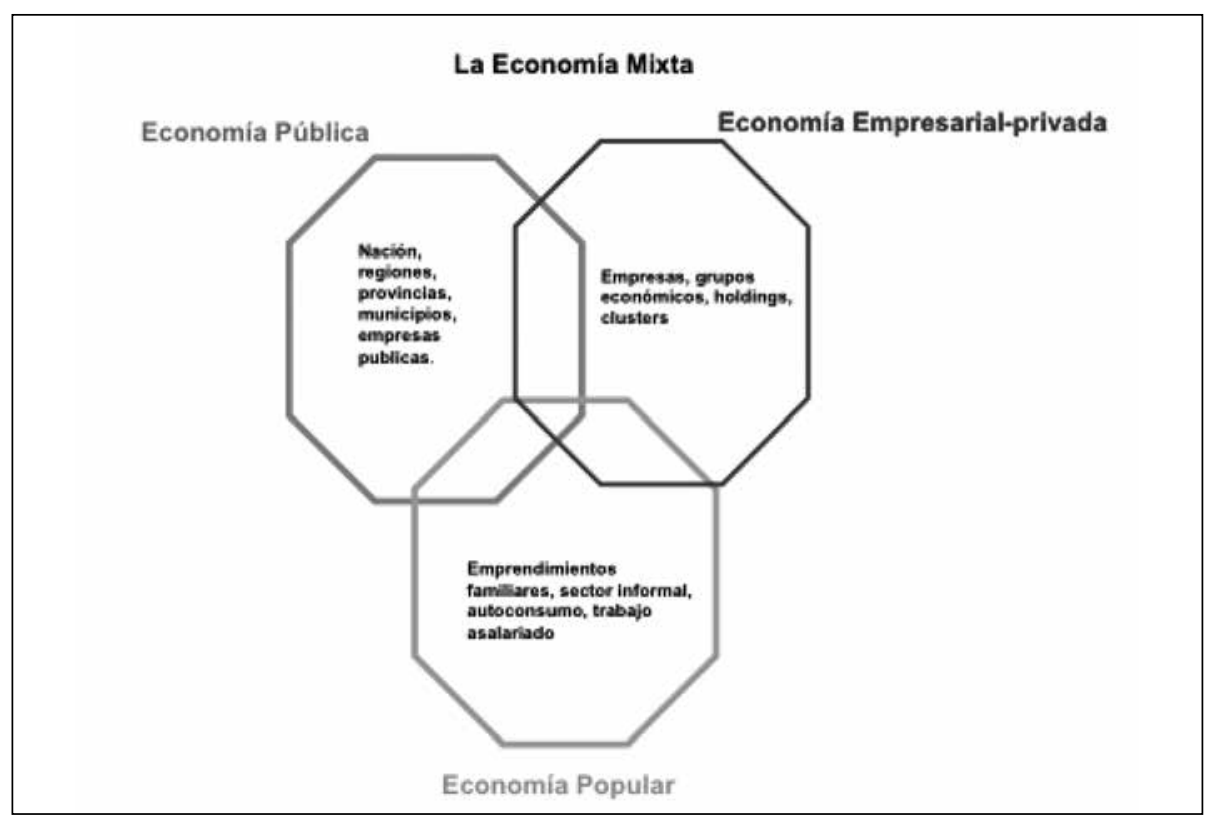


Las intersecciones entre los tres octógonos reflejan formas mixtas como una empresa cogestionada, o una empresa "mixta" (Privada-estatal), o una empresa de servicios públicos con participación de los usuarios.

El movimiento de conjunto de una economía mixta puede apreciarse por la dinámica cuantitativa y cualitativa que resulta de la aplicación de los recursos organizados o utilizados por la combinación de los diversos tipos de organización orientadas por los tres sentidos o grupos de sentidos mencionados. Esto puede ponderarse cuantitativamente, por ejemplo en base a los pesos relativos de cada sector para distintas variables (población ocupada, valor de la producción, demanda efectiva, contribuciones a los balances exteriores, etc.), o cualitativamente, por ejemplo según las negociaciones y conflictos en proceso entre agentes-sujetos de los distintos sectores pero sobre todo según las relaciones entre la base material (la economía) y la hegemonía o dominio políticos vigentes en la sociedad.

Entre los tres sectores hay intercambios mercantiles pero también transferencias unilaterales monetarias o no monetarias (subsidios, impuestos, donaciones, bienes públicos, remesas, etc.) cuya evolución, estructura y tendencias deberemos estudiar en cada caso concreto.

\section{LA UBICACIÓN DE LA ECONOMÍA SOLIDARIA EN LA ECONOMÍA MIXTA}

Nuestro punto de partida es siempre una economía mixta. En nuestros países es una economía mixta periférica con dominancia capitalista. Es decir que, aunque hay contradicciones, la lógica del capital subordina los otros sentidos presentes en el sistema económico.

Si tenemos que ubicar el sector de economía solidaria en la economía mixta lo podemos hacer como se refleja en el diagrama siguiente. Hay componentes solidarios en la economía popular, pero esta no es siempre ni predominantemente solidaria. Los hay, muy importantes, en la economía pública (principalmente las relaciones de redistribución progresiva). Y los hay también en el sector empresarial privado (aunque sea una solidaridad filantrópica y unilateral).

En este diagrama hay una tensión (flechas azules) por la lucha contrahegemónica contra la dominancia de la lógica capitalista. Se avanza ampliando el sector de economía solidaria articulándolo como un subsistema orgánico, construido desde el piso fértil de recursos y relaciones de reciprocidad y redistribución de la economía pública y la popular y ampliando su sentido del de la reproducción de la vida de los miembros de cada UD al de la reproducción ampliada de la vida de todos (solidaridad). 


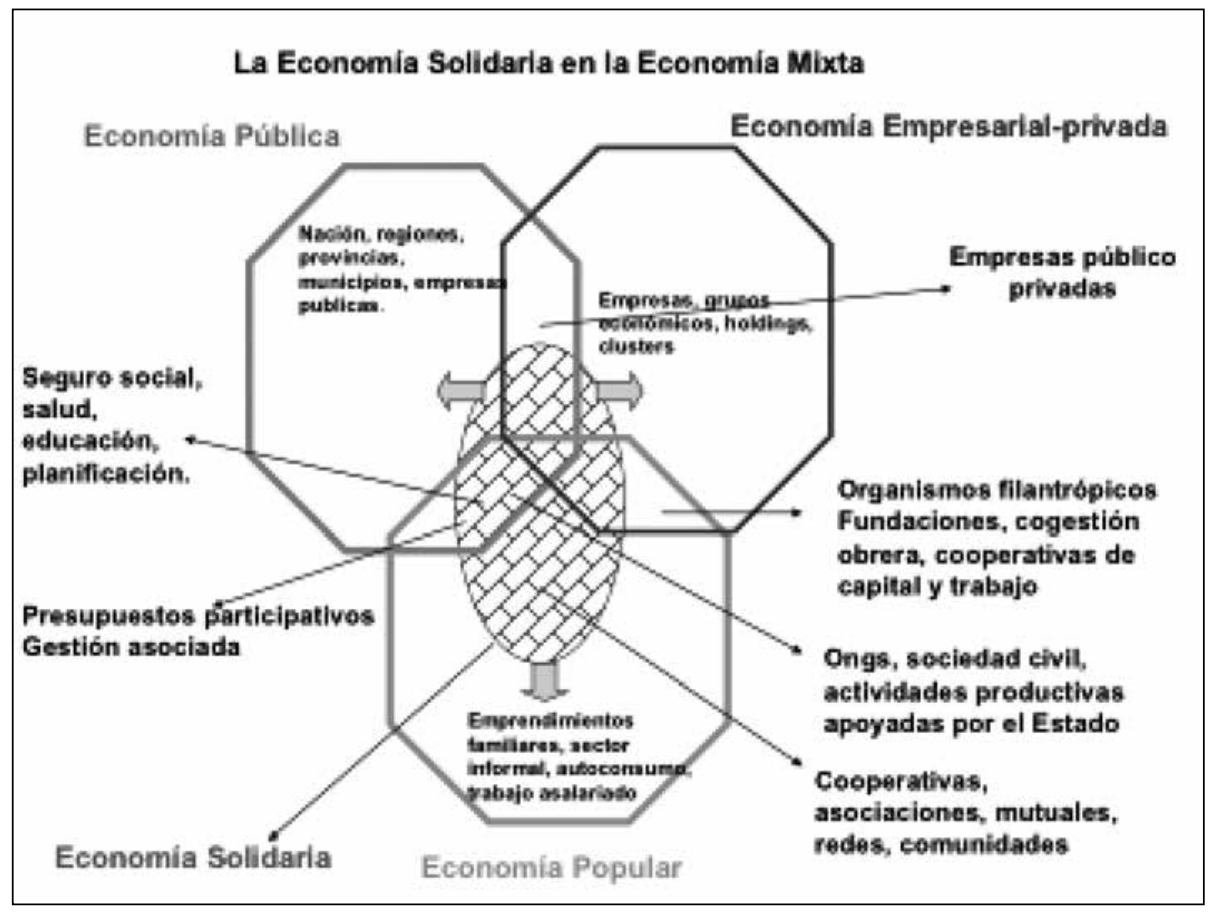

Esta economía mixta sigue teniendo los tres sectores, en particular el capitalista privado, pero con otros pesos, formas de organización y roles, y las líneas de fuerza amplían sus fronteras no sólo por la lucha por recursos y mercados, sino por acción del proyecto contra-hegemónico, tomando contenidos de democratización del estado, de resistencia al clientelismo político y de avance de los derechos ciudadanos, de avances en la legitimación de la reapropiación de recursos y actividades por los trabajadores, las comunidades o el Estado democrático, así como de institucionalizar otros límites morales a las acciones de los agentes del capital (provisoriamente, podríamos ejemplificar esta situación como la actual de los procesos en Bolivia, Ecuador y Venezuela).

Los trabajadores organizados necesitan no solo trabajar y sindicalizarse para defender el salario nominal y las condiciones de trabajo, o asociarse como productores autónomos para lograr mejores términos de intercambio en el mercado, sino ejercer fuerza en el conjunto del campo de relaciones de la economía mixta (por ejemplo: las movilizaciones de protesta o los movimientos organizados de usuarios de servicios que pugnan por el acceso, por la gratuidad, o por evitar aumentos en los precios de bienes y servicios públicos esenciales para la subsistencia). Para que el estado aporte a la expansión y profundización del subsistema de economía solidaria se requiere que las fuerzas políticas en el gobierno tengan un proyecto en tal sentido, superando las tendencias cortoplacistas y clientelistas. Y todo esto tiene que ver con la política.

La economía popular no es un mundo cerrado. Tampoco es un mundo de sumatoria de unidades o emprendimientos "micro-socioeconómicos", sino que hay redes que operan a nivel "meso-socioeconómico", como las redes de ayuda, asociaciones de productores que compran insumos, o comercializan, o generan ahorros y se dan crédito juntos, intercambios que pueden ser regulados a través de relaciones mercantiles, pero también de reciprocidad, de ayuda mutua. Esto es también parte de una Economía Popular, son extensiones de las UD y sus micro-emprendimientos. 
Sin embargo, no llega a constituir un subsistema, y avanzar en esa dirección implica ampliar el alcance de las relaciones de solidaridad.

El mercado no es exclusivo de la economía empresarial privada, en ocasiones mal denominada sector de mercado. El mercado atraviesa también la economía popular y puede generar comportamientos extremadamente competitivos, como en el denominado "sector informal urbano". En la situación de exclusión masiva y de dificultad para la reproducción que se ha agravado estos años, han resurgido formas de organización de mercado, como las ferias, por ejemplo, que son una forma de institucionalizar el intercambio como centro de encuentro directo y solidario entre productores y consumidores.

En general esta economía popular no vende bienes y servicios a la economía pública, porque la economía pública está formateada con créditos del Banco Mundial que indican que las compras del Estado tienen que ser licitaciones internacionales para que haya "competitividad". Por eso una reivindicación de los propulsores de la economía popular mercantil es la modificación de las reglas de compra del estado, facilitando la inclusión de pequeñas y medianas organizaciones, especialmente cooperativas. Tiene que existir un reconocimiento previo del papel de esta economía popular para que el poder social y del Estado se oriente a que ésta se supere y desarrolle otras formas, otras capacidades y calidades.

Hay también transferencias de valor o abiertamente monetarias entre la economía pública y la popular. Los subsidios a los servicios o las transferencias de ingresos mínimos a desocupados o pobres, que han estado difundiéndose como nueva política social, van en esa dirección; pero también hay una transferencia en sentido inverso: el pago de impuestos, muchas veces con gran inequidad fiscal.

Deberíamos poder hacer un análisis más macro de los términos de intercambio que se dan entre estas economías, la economía popular, la economía empresarial, la economía estatal, y además con la economía internacional, pero la falta de reconocimiento de la economía popular hace que sea difícil rastrear sus resultados y movimientos económicos agregados. Un ejemplo claro de esto es el trabajo doméstico de reproducción (cocina, lavado, limpieza, cuidado de las personas, confección y arreglo de vestimenta, autoconstrucción de la vivienda, etc.), usualmente realizado por la mujer, que no es reconocido como actividad económica ni se contabiliza en el PIB porque no se intercambia por dinero ni está mercantilizado (el sistema de registro contable nacional de Francia ha estimado que puede alcanzar al 40\% del PIB!). En el caso de Ecuador se está avanzando en este reconocimiento. Tanto por el lado del registro por el Banco central que mide el producto nacional como por las políticas de asignación de ingresos y pensiones a las mujeres que se han dedicado a la economía doméstica.

En resumen: el enfoque meso-socioeconómico permite superar la reducción al microemprendimiento al mirar lo micro desde una visión de la articulación económica posible en base a relaciones de solidaridad. Asimismo conlleva una visión del sistema económico (economía mixta) en el cual pude conceptualizar la ubicación de la economía popular realmente existente y su potencial como parte de un sector/ subsistema de economía solidaria. Advierte la necesidad de la lucha contrahegemónica dentro del sistema con predominancia capitalista buscando modificar las estructuras para ampliar la economía solidaria y poniendo límites a los otros dos sectores/ subsistemas. 
3. Una tercera corriente, que piensa y actúa también a nivel sistémico, va más allá de la propuesta de construir un subsistema de ESS dentro de una economía mixta. Procura la construcción de Otra Economía (otro sistema económico). ${ }^{7}$

Aquí se trata de buscar formas de "superación" del sistema cultural capitalista, que impulsa no sólo la crítica teórica y práctica de las relaciones de explotación capitalista del trabajo sino también las propias del patriarcado y otras formas de explotación, y pretende establecer una relación de contradicción y conflicto continuo con la economía del capital y la estatal. Esto implica no sólo diferenciarse y separarse sino proponerse como forma superior a las prácticas propias del capital, disputando el sentido de criterios, prácticas, propuestas a nivel micro y mesosocioeconómico, en una lucha donde economía, política y cultura se ven fuertemente imbricadas.

Se trata de construir otro sistema económico (Otra Economía), que substituya al actual, sobreconformando las relaciones de competencia entre intereses particulares con relaciones de redistribución, solidaridad y reciprocidad y el predominio de un bien común legítimamente establecido. En la transición, se puede hablar de una "economía plural". La definición de esa economía plural tendría que saldar debates importantes respecto a, entre otros: el papel del estado, el grado admitido de automatismo de mercado, las formas de propiedad y apropiación, el papel y control del dinero y el grado de mercantilización del trabajo y la naturaleza, así como a los valores morales propugnados como constitutivos de la nueva economía. En todo caso, no está claro ni es fácilmente decidible si se presenta como un principio de utopía o como una propuesta de economía realizable. Las instituciones de esa otra economía no están predeterminadas ni han sido deducidas de la crítica al capital, ni se saldan con la discusión sobre el socialismo como transición ya experimentada. En todo caso hay un largo proceso de acción experimental, recuperación histórica, producción teórica y aprendizaje, donde las ideologías cristalizadas y autoreproductivas no ayudarían mucho.

Un ejemplo "duro" de esta postura sería el de la economía socialista centralmente planificada que se inventó en la URSS y luego se modeló e implantó (con algunas variantes) en Cuba. Otra menos "dura" es la del estado de bienestar desarrollado en la posguerra en Estados Unidos y Europa, luego importado en versión lavada en nuestra región como estado desarrollista. Aún otra, menos explícita como sistema complejo, fue la propuesta de Marcel Mauss - o ahora de Paul Singer - de construir un "mundo de cooperativas", que algunos vinculan con la experiencia del socialismo yugoslavo. ${ }^{8}$ Posteriormente, Mauss revisó su posición, indicando que no es posible imponer a la realidad un paradigma de cambio, sino que a lo sumo la ley (digamos el estado) solo puede sancionar a partir de realidades, de prácticas existentes, y que la sociedad real tiene una diversidad que no pueden reducirse imponiendo un modelo uniforme. Esto cualifica el postulado de que es posible construir otra economía; es posible, pero no será diseñando prototipos y sobre-imponiéndolos a la realidad, en una suerte de ingeniería social. Y esto tiene que ver con la política. ${ }^{9}$

En todo caso, ya no se trata "sólo" de proponer la construcción y desarrollo de un subsistema dentro de otro sistema, de reestructurar una economía mixta teniendo en cuenta, claro está, las vinculaciones de la economía solidaria con el resto, es decir con el sector empresarial, con el estado, con la economía popular, tal como caracterizamos la segunda corriente. Aquí se trata de la relación de conjunto entre los campos de la
7 Ver: Diccionario de la Outra Economía, David Cattani, José L. Coraggio, Jean-Louis Laville (Org.), UNGS/ALTAMIRA/ CLACSO, Buenos Aires, 2009.

8 Ver: Paul Singer, Economía solidaria. Um modo de producción y distribución, em J.L. Coraggio (Org.), La economia social desde la periferia. Contribuciones latinoamericanas, UNGS/ALTAMIRA, Buenos Aires, 2007.

9 Sobre esto puede verse, José Luis Coraggio: La construcción de otra economía como acción política $(2013$ inédito). Disponible en: $<$ www.coraggioeconomia. org $>$. 
10 Ver: Franz Hinkelammert y Henry Mora, Economía, sociedade y vida humana. Preludio a una segunda crítica de la economia política, UNGS/ALTAMIRA, Buenos Aires, 2009. sociedad, de la economía, de la cultura y de la política, y de su posicionamiento en el sistema interestatal global.

Implica pugnar por revertir la autonomización del mercado, profundizada por el neoliberalismo, avanzando en su regulación desde la sociedad y la política, sin caer en la absolutización del principio de planificación [se trata de ir a una sociedad con mercado, no de mercado].

Implica redefinir los mecanismos y alcances del principio de redistribución de dinero y bienes públicos, incorporando la redistribución de la tierra, del agua, del conocimiento, el control del dinero como bien público y no como mercancía. Sin embargo, con respecto a esto último, no se trataría sólo de distribuir de otra manera lo existente, sino de revisar las reglas de apropiación y disposición de los medios productivos. Supone no sólo redistribuir (algo que hoy caracteriza a los gobiernos de sentido popular, no necesariamente autodenominados revolucionarios, en América Latina) sino transformar la estructura productiva interna (qué y cómo se produce), los modos de legitimación de las necesidades y de consumo y las relaciones externas (grado de soberanía alimentaria, energética, financiera...). ${ }^{10}$

Incluye claramente redefinir las relaciones entre sociedad y naturaleza. Implica reestructurar el sistema de generación de conocimiento científico y tecnológico, hoy orientado a producir conocimientos patentables privadamente para hacer negocios, y el sistema educativo en su conjunto... Una última característica de esta corriente virtual que estamos delimitando es la de que, antes que concentrarse en el alivio de la pobreza a través de la redistribución del excedente generado por un crecimiento acelerado, plantea la inseparabilidad de la continuidad de la pobreza a pesar del crecimiento económico, por un lado, y la creciente concentración de la riqueza por el otro. Y no se limita a lograr un gobierno que negocie mejores condiciones en los intercambios con el sector empresarial, sino que ataca las consecuencias de la primacía de las corporaciones por sobre la política democrática.

\section{LA NECESARIA ARTICULACIÓN Y MUTUO RECONOCIMIENTO DE LAS TRES “CORRIENTES" DE LA ESS}

Para dar otro ejemplo: ubicados en la primera corriente esperaríamos que la universidad desarrolle incubadoras o asesorías puntuales gratuitas a los emprendimientos que van surgiendo; en la segunda corriente pugnamos para que el subsistema local de ESS establezca otra relación con la universidad regional, pudiendo establecer algunos convenios menos puntuales, procesos de formación específicos para los actores de la ESS. En la tercera corriente ya se plantea revolucionar la universidad como institución y sus relaciones con la sociedad como un todo, y por tanto su relación con el conocimiento (a su vez sometido a crítica en tanto absolutización de la ciencia), la formación y los servicios. Pero además conlleva recuperar su papel de institución del intelecto, es decir que sea no sólo instrumental, útil, sino lugar de reflexión crítica de la realidad existente.

Estas tres corrientes tienen, claramente, un alcance distinto y proyectan de otra manera el accionar si se asume uno u otro horizonte. Sin embargo, las tres 
son significativas, en cierto sentido se necesitan mutuamente. Lógicamente es en base al aprendizaje enfrentando los desafíos del primer nivel que surgen los problemas conceptuales y prácticos que llevan al segundo y así siguiendo. Como en la realidad hoy los tres coexisten, parte de la tarea política es dialogar y lograr alianzas, vincular la atención de la urgencia inmediata con la mirada estratégica, analizar en cada situación concreta el papel que cada tipo de intervención o proyecto puede tener en el movimiento de conjunto.

Para admitir esto es muy importante revisar la dinámica de estos procesos. El nivel de prácticas integradoras al mercado laboral, si no tiene intereses espurios, lleva necesariamente a advertir la necesidad del segundo nivel, y éste, al avanzar, encuentra limites que sólo pueden franquearse si se pasa el nivel tres. O, la lectura inversa: no es posible pretender transformar toda la economía por la ley, aunque sea una Constitución, si no hay actores microsociales predispuestos a resignificar sus acciones, o si no hay subsistemas que no solo movilicen recursos, personas y comunidades sino que den una base firme a la formación de sujetos colectivos que sustenten el proyecto de construcción de otra economía. (Nuevamente: Bolivia, Ecuador, Venezuela)

Sin embargo, la falta de diálogo y la competencia pueden dar lugar a antagonismos cuando los actores de una u otra corriente se posicionan ideológicamente defendiendo su práctica a rajatablas y viendo las otras como "poca cosa" (si es que no "funcionales al sistema") o, a la inversa, como utópicas o "políticas".

En definitiva, las llamamos "corrientes" en tanto entre los actores de la ESS predomina una u otra práctica y visión del alcance de la ESS. Sin embargo, visto desde la "corriente 3", se trata de tres niveles de intervención que se necesitan mutuamente para poder concretarse. Se puede actuar al nivel 3, pero sin el piso de las prácticas del nivel 2 y 1 no podría pasar de ser un proyecto estatizante. Se puede actuar al nivel 1, pero sin el nivel 2 se pierde eficacia y sostenibilidad. Si no se llega al nivel 3, las realizaciones a nivel 1 y hasta 2 pueden quedar aislados o subordinados dentro de una economía donde predomina el principio de mercado.

Finalmente, hay que tener presente que estas tres corrientes especificamente identificadas desde la perspectiva de las visiones y prácticas de la ESS, pueden estar atravessadas por corrientes y proyectos ideologico-políticos particulares orientados, por ejemplo, por la acumulación de poder partidario, o por la emancipación humana. Por lo pronto, no presumimos que haya uma correspondência unívoca entre el pensamento sistémico y una orientación de izquierda, ni que la acción a nível microeconómico relativamente alienada sea de por sí politicamente regresiva. Los tres niveles pueden darse dentro de proyectos de motivación utilitarista o de afirmación del reconocimiento del otro y la solidaridad democrática. Esto tiene que ver com la política.
José Luis Coraggio é Investigador y Docente del Instituto del Conurbano, Universidad Nacional de General Sarmiento (UNGS). E-mail: <jlcoraggio@me.com> 


\section{REFERÊNCIAS BIBLIOGRÁFICAS}

CAIllÉ, A.; LAVILlE, J.-L.; FERRATON, C.; CORAGGIO, J. L. (orgs.), ¿Qué es lo económico? Materiales para un debate necessario contra el fatalism. Buenos Aires, ICCUS, 2009.

CATTANI, D.; CORAGGIO, J. L.; LAVILLE, J.-L. (org.s). Diccionario de la outra economía. Buenos Aires, UNGS/ALTAMIRA/CLACSO, 2009.

CORAGGIO, J. L. La construcción de otra economía como acción política. (inédito). Disponible en www.coraggioeconomia.org.

CORAGGIO, J. L. Economía y política: sobre la sostenibilidad de los emprendimientos mercantiles de la economía social. In: CORAGGIO, J. L. Economía social: acción pública y política. Buenos Aires, CICCUS, 2007.

HINKELAMMERT, F; MORA, H. Economía, sociedade y vida humana: preludio a una segunda crítica de la economia política. Buenos Aires, UNGS/ALTAMIRA, 2009.

LAVILLE, J.-L. (Comp.). Economía social y solidaria: uma visión europea. Buenos Aires, UNGS/ALTAMIRA, 2004.

SINGER, P. Economía solidaria: um modo de producción y distribución. In: CORAGGIO, J. L. (org.). Economía social desde la periferia: contribuciones latinoamericanas. Buenos Aires, UNGS/ALTAMIRA, 2007.

A B S T R A C T This paper aims to critically revisit the existence of different approaches currently adopted in the field of popular economy both in the level of theories and actions. Three approaches are presented here and each one sustains different practices and conceptions regarding the reach of the popular economy. The first approach seeks the reinsertion through work and acts in a microeconomic level focusing on poverty relief. The second one promotes the creation of an organic sector (subsystem) of the popular economy while underscores the sustainability and efficiency of the enterprises. In turn, the third approach thinks and acts in a systemic level, proposing the construction of Another Economy. This latter approach comprises three levels of intervention that are mutually interdependent.

K E Y W O R D S social and solidarity economy (SSE); popular economy; mixed economy; plural economy; counter hegemonic struggles; Another Economy. 